\title{
Antiseizure Drugs and Reduced Bone Density
}

Robert A. Gross, MD, PhD; Barry E. Gidal, PharmD; and Alison M. Pack, MD

\section{A New Look at Bone Health}

Osteoporosis is a disorder associated with low bone density. Bone density is the term used to describe how thick or strong bone is. In this issue of Neurology ("Antiepileptic Drug Use Increase Rates of Bone Loss in Older Women: A Prospective Study"), a research team consisting of epilepsy specialists and epidemiologists (persons who study the causes and control of diseases) reports on a study that answered an important but simple question: Do antiseizure drugs cause reductions in bone density? Why ask this question? Most doctors and patients agree that controlling seizures is very important-possibly the most important considerationbut other issues, such as long-term side effects of a medication, may affect quality of life. If a drug reduces bone density, bones will become more fragile, and eventually this could result in fractures that may have a major effect on health and quality of life. More information about how to keep bones healthy can be found on the next page.

The main result of the study was that women taking antiseizure drugs were more likely to have reduced bone density than women who were not taking this group of medications. In particular, phenytoin (Dilantin, Pfizer, New York, NY) was associated with significant bone loss.

To find this out, the researchers studied a large number of older women $(>9,700$ women, aged 70 years on average) who were regu- larly assessed for bone health with bone density scans (which measure how thick and sturdy bone is) at the spine, heel, and hip. Because women of this age are already at risk for thin bones and because some of them may have been taking antiseizure drugs, they were an ideal group to study. A lot of other information was collected about these women, including their intake of calcium and vitamin D, their level of activity, other medical conditions, smoking, height, and weight. This was helpful because these can affect bone health; therefore, the researchers took these factors into account so that only the drug effect was determined. Bone density in women who never took antiseizure drugs was compared with bone density in women who had taken these drugs sometimes or continuously.

Women who took antiseizure drugs regularly (mostly phenobarbital, phenytoin, primidone [Mysoline, Wyeth, Madison, NJ] and carbamazepine [Tegretol, Novartis, Basel, Switzerland; or Carbatrol, Athena Neurosciences, South San Francisco, CA]) had a nearly 50\% greater rate of bone loss per year $(0.7 \%$ per year for nonusers and $1.16 \%$ per year for regular users). The rate of bone loss was almost two times greater per year for those who took phenytoin. This increased rate of bone density loss has the potential to increase the rate of fractures. Importantly, regular users of antiseizure drugs would have an estimated $29 \%$ increase in hip fractures over 5 years.
This study raises more questions. What about rates of bone loss in younger women, children, and men? What medications have this effect? How long does someone need to be on medication to see an effect on bone? Once bone loss occurs, is it treatable? These questions and others will need additional studies to find definite answers.

What can you do now? Based on a survey, many primary care providers and neurologists do not regularly ask their patients with seizures about bone health. Therefore, talk to your doctors about bone health. Simple blood and bone density tests can be done to find out if you are at risk for or actually have reduced bone density. Discuss lifestyle and all those things that can influence bone health: other medical conditions and medications, habits such as smoking and drinking alcohol, and the importance of keeping physically active and getting sunlight exposure (within reason). Should you be taking something to maintain bone health, such as calcium and vitamin D supplements? Should a bone specialist help in evaluation and treatment? The following page will tell you more about bone health and the various measures you can take to help maintain healthy bones. Finally, remember that when choosing an antiseizure medication, bone health is one factor among many. Your neurologist or epilepsy specialist will help find the right medication for you. 
Disorders of bone, such as osteoporosis (reduced bone density), have become a major public health concern. In the United States alone, approximately 10 million individuals have osteoporosis, and it is estimated that approximately 34 million have some degree of low bone density. Contrary to popular belief, osteoporosis, a disorder once considered to be a normal part of aging in women, is no longer considered related to age or gender. Younger women and men may develop osteoporosis from other causes, such as medications or illnesses.

There are many related factors that influence bone health, including genes, diet, exercise, and exposure to the sun. Of these secondary causes, certain medications, including certain antiseizure drugs, are now recognized as common culprits.

Throughout childhood, bone mass (the amount and thickness of bone) continues to increase until about age 30 years. After this age, bone density slowly decreases. A balance of bone breakdown and bone formation determines bone density.

Other disorders of bone formation, including rickets and osteomalacia, have also been described in patients treated for epilepsy. Rickets is a condition that occurs in children when bone does not grow properly (at the "growth plate") and is not properly mineralized with calcium, resulting in deformity of bones. Children with rickets also have low muscle tone and muscle weakness. Rickets occurs because the levels of calcium, phosphate, or vitamin D are low. Rickets is a disorder that occurs before the cessation of growth.

Osteomalacia occurs after bone growth is completed (in contrast to rickets) and results from a reduction in bone mineralization. Drugs that interfere with the absorption or metabolism of either calcium or vitamin D can lead to osteomalacia. Persons with osteomalacia may have muscle or generalized bone pain. Like osteoporosis, bone strength is reduced and the risk of fracture is therefore increased with rickets and osteomalacia.

Early studies found rickets in children taking antiseizure drugs for epilepsy. Osteomalacia was also found in early studies. Neither rickets nor osteomalacia has been consistently found in more recent studies. It is likely that the results of the early studies were affected by other factors such as poor diet and lack of exposure to the sun.

Osteoporosis has been found in men and women taking antiseizure drugs. Osteoporosis is a bone disorder that is characterized by decreased bone density and deterioration, leading to increased fragility of bone. Importantly, over time, this reduction in bone mineral density and the resulting increase in bone fragility can lead to an increased risk of bone fractures, including fractures of the hands, arm, legs, vertebrae, and hip.

Osteoporosis is diagnosed by a determination of bone density. Presently, bone density is best measured using a readily available test called dual energy $\mathrm{x}$-ray ab- sorptiometry (DEXA). Low bone density has been found in DEXA scans of persons with epilepsy taking antiseizure drugs.

Increased fractures are seen in persons with epilepsy taking antiseizure drugs. Although having a seizure, especially a convulsive seizure, may increase fracture risk, taking an antiseizure drug also likely increases the risk because of its effect on bone. Indeed, increased rates of fracture have been seen in patients who did not apparently have a seizure at the time of injury.

The antiseizure medications known to affect bone include phenytoin, primidone, and phenobarbital. The data for carbamazepine and valproate are not as clear; however, some studies have suggested they may affect bone in certain patients. There are no definite data for the effect of the newer medications, including gabapentin (Neurontin; Pfizer); tiagabine (Gabitril; Cepahlon); lamotrigine (Lamictal; GlaxoSmithKline); topiramate (Topamax; Ortho-McNeil); oxcarbazepine (Trileptal; Novartis); zonisamide (Zonegran; Elan); and levetiracetam (Keppra; UCB Pharma).

\section{For more information}

\section{American Academy of Neurology Foundation www.thebrainmatters.org}

National Institutes of Health Osteoporosis and Related Bone Diseases National Resource Center www.osteo.org 


\section{Neurology}

\section{Antiseizure Drugs and Reduced Bone Density}

Robert A. Gross, Barry E. Gidal and Alison M. Pack

Neurology 2004;62;E24-E25

DOI 10.1212/01.WNL.0000129704.29460.FA

This information is current as of June 7, 2004

\section{Updated Information \&} Services

Permissions \& Licensing

Reprints including high resolution figures, can be found at: http://n.neurology.org/content/62/11/E24.full

Information about reproducing this article in parts (figures,tables) or in its entirety can be found online at:

http://www.neurology.org/about/about_the_journal\#permissions

Information about ordering reprints can be found online:

http://n.neurology.org/subscribers/advertise

Neurology $®$ is the official journal of the American Academy of Neurology. Published continuously since 1951, it is now a weekly with 48 issues per year. Copyright . All rights reserved. Print ISSN: 0028-3878. Online ISSN: 1526-632X.

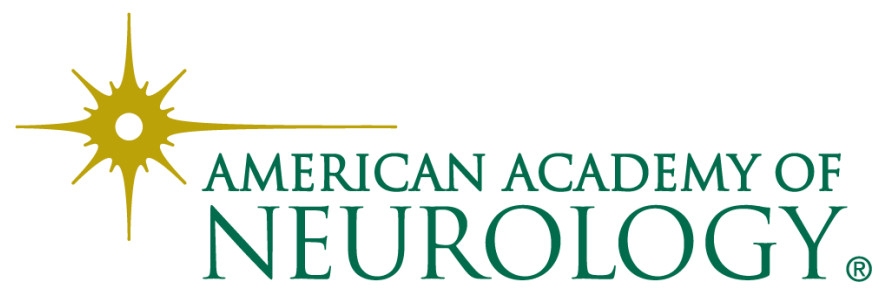

